\title{
Electromagnetic Energy Absorption due to Wireless Energy Transfer: A Brief Review
}

\author{
A. Syafiq ${ }^{1, *}, M . H . \mathrm{Mat}^{2}$, and $H . A$. Rahim $^{3}$ \\ ${ }^{1}$ School of Electrical System, UniMAP, Perlis, Malaysia \\ ${ }^{2}$ Centre for Diploma Studies, UniMAP, Perlis, Malaysia \\ ${ }^{3}$ School of Computer \& Communication Engineering, UniMAP, Perlis, Malaysia
}

\begin{abstract}
This paper reviews an implementation of evaluating compliance of wireless power transfer systems with respect to human electromagnetic exposure limits. Methods for both numerical analysis and measurements are discussed. The objective is to evaluate the rate of which energy is absorbed by the human body when exposed to a wireless energy transfer, although it can be referred to the absorption of other forms of energy by tissue. An exposure assessment of a representative wireless power transfer system, under a limited set of operating conditions, is provided in order to estimate the maximum SAR levels. The aim of this review is to conclude the possible side effect to the human body when utilizing wireless charging in daily life so that an early severe action can be taken when using wireless transfer.
\end{abstract}

\section{Introduction}

Wireless power transfer (WPT) or wireless energy transmission is the transmission of electrical power from a power source to a consuming device without using any of discrete conductors. Nowadays, there is recent interest regarding battery charging wireless power transfer technology are now being seen by the ubiquity of cellular phone phones, automotive and the other type of mobile communication devices. Recently the concern about wireless electromagnetic waves are being concerned with communication devices. Wireless charging, as well known as inductive charging, which is suitable to shoot up your smartphone. Wireless chargers emit an alternating current by a transmitter coil, which induces a voltage in the receiver coil found in the device. Hence, the pace was quantified by the power absorbed with a limited arena of the body tissue in a standard measurement of watts per kilogram $(\mathrm{W} / \mathrm{kg})$. It can be an average measure over the intact body, or a small sample amount such at the hand by the Specific Absorption Rate (SAR). The Specific Absorption Rate (SAR) measures exposure within range of the frequency $100 \mathrm{kHz}$ and 10 $\mathrm{GHz}$, such as laptops, wireless charger, Wi-Fi routers and cell phones.

\footnotetext{
${ }^{*}$ Corresponding author: aliffsyafiqjamaluddin@yahoo.com
} 


\section{Specification absorption rate}

Specific absorption rate (SAR) signifies a measurement for an electromagnetic energy that absorbed by the biological tissue in case by the different type of exposure such as wireless, transmitter, antennas, and phones [1-2]. The SAR limit were specified in the IEEE C95.1: 1999 are $1.6 \mathrm{~W} / \mathrm{Kg}$ in a SAR1gm averaging mass while that specified in IEEE C95.1: 2005 has been updated to $2 \mathrm{~W} / \mathrm{Kg}$ in a $10 \mathrm{gm}$ averaging mass [3]. This new SAR limit specified in IEEE C95.1 : 2005 is comparable to the limit specified in the International Commission on Non-Ionizing Radiation Protection (ICNIRP) guidelines. That's why the Specific Absorption Rate (SAR) will be calculated and be measured in this project to achieve the safety using wireless power transfer to human mankind. The basic property for assessing local RF exposure from wireless devices is the Specific Absorption Rate (SAR). So, the Specific Absorption Rate (SAR) testing is conducted by according to international standards regularly as part of the product type approval.

$$
\mathrm{SAR} \cdot=\cdot \frac{\sigma}{\rho} E^{2}\left(\frac{W}{k g}\right)
$$

The Specific Absorption Rate (SAR), which can cause the heating of tissue were measured in Watts per kilogram and its measure of electromagnetic energy absorption by the body [5]. By $\sigma$ is the electric conductivity of the tissue in $\mathrm{S} / \mathrm{m}, \rho$ is the mass density in $\mathrm{Kg} / \mathrm{m}^{3}$, and $\mathrm{E}$ is the root-mean-square (rms) magnitude of the electric field strength in $(\mathrm{V} / \mathrm{m})$ inside the material [6]. Then, we can calculate the SAR by using this equation. The SAR of a human body exposed to RF-EMF which it is very difficult to measure directly because the SAR includes the internal electric field strength and conductivity of the body, so the equation above will be used for measure [7]. Therefore, Specific Absorption Rate (SAR) be situated estimated by numerical methods using computational models of human bodies.

\section{Electromagnetic theory}

The acronym EMF (Electromagnetic Fields) is commonly used to express the exposure of humans to electromagnetic fields. The exposure to EMF is covers a wide frequency range from $(0 \mathrm{~Hz}-300 \mathrm{GHz})$. Electromagnetic fields happens everywhere in our environment such as the earth, sun and ionosphere where this all natural sources of EMF.

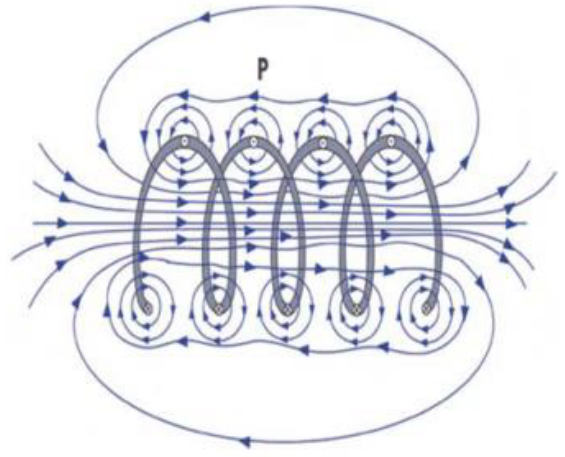

Fig. 1. Current through the coil (inductive charging) [9] 
From the Figure 1, the implanted coil directly provides the charging current for the pacemaker battery through transcutaneous electromagnetic induction between the coils [10]. The idea breaks on inductive coupling that uses an electromagnetic field where its transfers energy from the transmitter to the receiver [10]. There's an alternating current that passes through the coil in the charger, which creates a fluctuating electromagnetic field. This technique can powerfully transfer power over a relatively long distance using the resonators by having the high quality factor [11]. So, the coil in the contrivance is placed in this electromagnetic field where the current is induced in the coil and next charges the contrivance's battery. But, for charging, phones are required to keep near the charging plate, so it will using inductively coupled power transfer [12]. This is reason why wireless charging is sometimes kenned as inductive charging.

\section{Type and designation coil}

There many type of coils with a winding material (copper and iron), different size, and conductor cross-sectional. Simply, the coils with the ferromagnetic wire differ substantially from the coils with the diamagnetic material which their inductance and resistance are significantly higher, and it's depend substantially on the signal frequency. In a coil testing, with the frequency increase from $20 \mathrm{kHz}$ to $150 \mathrm{kHz}$ inductance of the ferromagnetic coil decreased by $9.86 \%$, while the copper wire coil inductance doesn't change [13]. Hence, the type of copper coil is use in this project.

\section{Wireless energy/power transfer and operation}

The very essential of any magnetic Wireless Power Transfer system are the magnetically coupled transmitting and receiving coils [14]. The wireless power transfer (WPT) system using magnetically coupled coils has been discovered by Kurs in 2007 [15-16]. When the alternating current is passed through transmitter coil, it's generate the magnetic field.

The receive coil and loop ( $\mathrm{Rx})$ are identical to the transmit coil and loop [17]. It will receive the transmit power from the (Tx) coil. The strong reactive near-fields of wireless power systems may induce high fields in the body tissue of persons in their closest vicinity. Wireless charging can be as efficient as a wired charging when receiver implements direct charging [18].

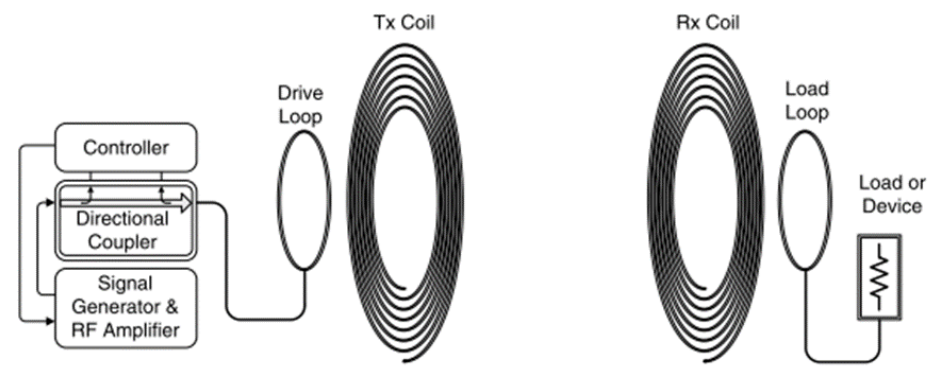

Fig. 2. Schematic block diagram for magnetically coupled resonant wireless power system [17] 


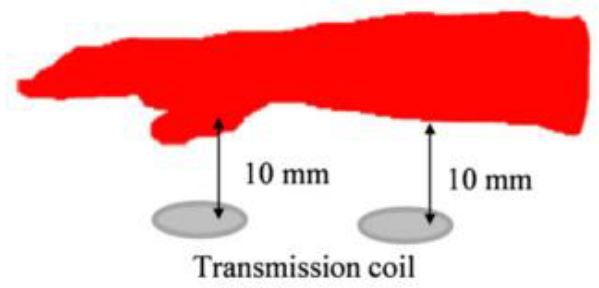

Fig. 3. Computational condition for the arm [19].

Figure 2 shows the exposure condition of the arm. The part of body human, arm was selected to perform in this simulation. Two positions of the transmitting coil in proximity to the hand and forearm are considered. This is because our hand was near when we charge our phone via wireless charging. The coil is located below the Palmar side of the hand or forearm at a distance of $10 \mathrm{~mm}$.

\section{Expected Results}

For the best result, the wireless transfer and human hand has been consider to confirm the magnetic field distribution generated by the transfer system. For the effects of this results, the wireless power transfer as charging phone has been used to work out the SAR exposure on the human torso. Note that the magnetic field distribution without the magnetic sheet is symmetrical. So, the disturbance in the field is mainly attributed to the insertion of the magnetic sheet.

\section{Summary}

In a nutshell, overall studies have investigated the SAR and the electric field in anatomically based human-body models of the magnetic field emitted from the wireless power transfer system with induction coupling. Thus, it is agreed that probably that the wireless power transfer has an effect in the human tissues due to an electromagnetic absorption.

\section{References}

1. C. Lazarescu, V. Dafinescu, V. David, International Conference and Exposition on Electrical and Power Engineering, 25 (2012)

2. R. Butet, Y. Toutain, and S. Le Dall, 2013 IEEE Antennas and Propagation Society International Symposium (APSURSI), 2026 (2013)

3. I. International and E. Safety, IEEE Standard for Safety Levels with Respect to Human Exposure to Radio Frequency Electromagnetic Fields, $3 \mathrm{kHz}$ to $300 \mathrm{GHz}$, (IEEE Standards, 2006)

4. S. Akimoto, S. Kikuchi, T. Nagaoka, K. Saito, S. Watanabe, M. Takahashi, K. Ito, IEEE transactions on microwave theory and techniques, 58, 3859 (2010)

5. B.M. Hochwald, D. J. Love, S. Yan, P. Fay, J. Jin, and B. M. Hochwald, IEEE Communications Magazine, 52, 126 (2014)

6. B.A. Christ, M. Douglas, S.M. Ieee, J. Nadakuduti, M. Ieee, N. Kuster, F. Ieee, Proceedings of the IEEE, 101, 1482 (2013)

7. T. Nagaoka and S. Watanabe, Electromagnetic Compatibility (EMC EUROPE), 2013 International Symposium on. IEEE, 891 (2013) 
8. S. Nishizawa, S. Member, and O. Hashimoto, IEEE transactions on microwave theory and techniques, 47, 277 (1999)

9. S. Garg and F. Khan, Int. J. Multidiscip. Res. Dev., 2, 650 (2015)

10. J. C. Lin, IEEE Antennas and Propagation Magazine, 55,251 (2013)

11. S. Park, H. Kim, J. Cho, and E. Kim, 2014 International Symposium on Electromagnetic Compatibilit, 1190 (2014)

12. P. Kumar, International Journal of Engineering Science and Innovative Technology, 2, 215 (2013)

13. A. Laizans, A. Galins, V. Osadcuks, A. Pecka, A. Rubenis, Proceedings of the international scientific conference (Latvia University of Agriculture, 2015)

14. R. Pinto, M. Bertoluzzo, V. Lopresto, S. Mancini, C. Merla, G. Pede, A. Genovese, and G. Buja, 2015 9th European Conference on Antennas and Propagation (EuCAP), 1 (IEEE, 2013)

15. A. Kurs, A. Karalis, R. Moffatt, J. D. Joannopoulos, P. Fisher, and M. Soljac, Sci., 317, 83 (2007)

16. J. Chakarothai, K. Wake, and S. Watanabe, General Assembly and Scientific Symposium (URSI GASS), (IEEE, 2014)

17. A. Christ, M.G. Douglas, J.M. Roman, E.B. Cooper, A.P. Sample, B.H. Waters, J.R. Smith, N. Kuster, IEEE Trans. Electromagn. Compat., 55, 265 (2012)

18. T. Bijalwan, R. Parveen, P. Uniyal, Kavita Panwar, A. Bagwari, ISTP Journal of Research in Electrical and Electronics Engineering, 212, 2014.

19. T. Sunohara, A. Hirata, I. Laakso, T. Onishi, Phys. Med. Biol., 59, 3721 (2014) 